\title{
PENGARUH KEDALAMAN TERHADAP TAHANAN PENTANAHAN DI AREA RUSUNAWA KAMPUS UNIVERSITAS PGRI PALEMBANG
}

\author{
Nita Nurdiana ${ }^{1}$, Alimin Nurdin ${ }^{2}$, Dewa Aditya Putra Yoga ${ }^{3}$ \\ Program Studi Teknik Elektro, Fakultas Teknik, Universitas PGRI Palembang \\ Email: nurdiana78@univpgri-palembang.ac.id, \\ aliminnurdin@univpgri-palembang.ac.id, dewaaditya33@gmail.com
}

\begin{abstract}
ABSTRAK Nilai tahanan pentanahan dipengaruhi oleh kedalaman penanaman elektroda. Penelitian ini pengukuran dilakukan di Rusunawa Universitas PGRI Palembang dengan menggunakan metoda tiga titik dengan menanamkan batang elektroda pada kedalaman berbeda. Penelitian ini bertujuan untuk megetahui besarnya nilai pentanahan yang ada di daerah Rusunawa tersebut. Hasil penelitian ini menunjukka bahwa hasil pengukuran dan perhitungan menunjukkan semakin dalam elektroda ditanamkan maka akan semakin nilai tahanan jenis tanahnya sehingga nilai tahanan pentanahannya juga semakin kecil
\end{abstract}

Kata Kunci : elektroda, pentanahan, Metode Tiga Titik, tahanan pentanahan,

\begin{abstract}
Earth resistance value is obtained for electrode implantation In this study the measurement of earth resistance was carried out in the Rusunawa area of the PGRI University of Palembang. This study aims to determine the amount of grounding in the Rusunawa area. The results of this study indicate that the results of measurements and calculations show the deeper the electrodes are implanted, the more the resistivity value of the soil type so that the earth resistivity is also smaller
\end{abstract}

Keywords : electrode, Groundin, three-point methode, grounding resistance.

\section{PENDAHULUAN}

Sistem pentanahan merupakan suatu sistem dimana adanya sambungan antara suatu peralatan listrik atau titik netral dengan bumi baik secara langsung maupun melalui impedansi. Pada sistem pentanahan penting yang harus diperhatikan yaitu tahanan pada elektroda pentanahan, kondisi tanah, dan tahanan dari tanah di sekitar elektroda pentanahan.

Rusunawa Universitas PGRI Palembang merupakan suatu bangunan yang dimanfaatkan sebagai tempat tinggal yang di khususkan bagi para mahasiswa dari luar daerah. Bangunan ini berupa bnagunan bertingkat dua lantai. Bangunan bertingkat dinilai cenderung rawan dalam ganguan alam seperti sambaran petir.

Penelitian ini dilakukan untuk mengetahui nilai tahanan pentanahan dengan menanamkan elektroda batang pada tanah disekitar Rusunawa Universitas PGRI Palembang.

\section{TINJAUAN PUSTAKA}

Peranan sistem pentanahan atau pembumian sangatlah dalam suatu sistem proteksi. Pentanahan yang baik tidak hanya dapat mengamankan peralatan yang menggunakan sumber listrik, mengamankan komponen-komponen instalasi dari bahaya tegangan/arus abnormal tetapi juga dapat mengamankan manusia dari sengatan listrik. [1] 


\section{Tahanan Pentanahan}

Banyak hal yang mempengaruhi nilai tahanan pentanahan, Menurut Aris Sunawar [2] tahanan jenis tanah, batang pentanahan serta tahanan kontak antara batang pentanahan dengan tanah mempengaruhi nilai pentanahan. Dalam penelitian Muhammad Taqiyyuddin Alawiy[3] dan Ahmad Budiman [4], semakin kecil nilai tahanan pembumian maka semakin baik sistem pembumiannya. Pada kondisi tanah tertentu, nilai tahanan pembumian juga dipengaruhi oleh kedalaman penanaman elektroda. Menurut Hutauruk [5] nilai resistivitas tanah dapat bervariasi dari satu tempat ke tempat lain, tergantung pada sifat-sifatnya. Wahyono [6] dan penelitian Viki Salena [7] berpendapat sistem pentanahan jenis batang (rod), semakin dalam batang pentanahan ditanam kedalam tanah semakin kecil nilai tahanan tanahnya. Sehingga semakin kecil nilai tahanan pentanahan, maka pentanahan tersebut semakin baik. Sebagai pedoman dasar, tabel berikut berisi resistivitas tanah di Indonesia.

Tabel 1 Tahanan Jenis Tanah

\begin{tabular}{|c|l|c|}
\hline No. & \multicolumn{1}{|c|}{ Jenis Tanah } & $\begin{array}{c}\text { Tahanan jenis tanah } \\
\text { (ohm.meter) }\end{array}$ \\
\hline 1. & Tanah yang mengandung air garam & $5-6$ \\
\hline 2. & Rawa & 30 \\
\hline 3. & Tanah liat & 100 \\
\hline 4. & Pasir basah & 200 \\
\hline 5. & Batu-batu kerikil basah & 500 \\
\hline 6. & Pasir dan batu kerikil kering & 1000 \\
\hline 7. & Batu & 3000 \\
\hline
\end{tabular}

Sumber : IEEE std 142-1991[8]

\section{Elektroda}

Elektroda yang dapat digunakan dalam pengukuran pentanahan adalah elektroda batang, elektroda plat dan elektroda pita.
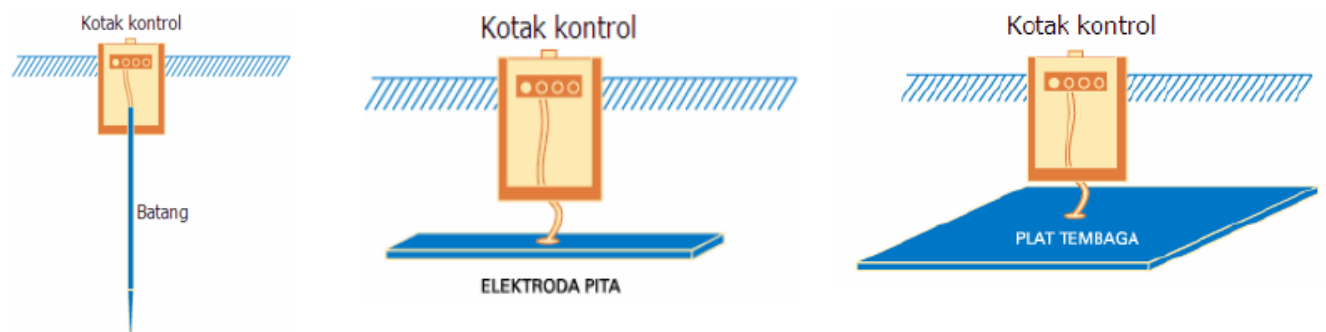

Gambar 1. Macam-macam Bentuk Elektroda [9]

\section{Metode Pengukuran Tahanan Jenis Tanah [10]}

\section{a. Metoda Empat Titik (four-point methode)}

Peralatan yang digunakan sebagai berikut:

- 4 batang pentanahan rod

- 1 buah ampere meter

- 1 buah volt meter sumber daya AC

Cara penyambungan:

4 batang besi (sebut saja sebagai batang C1, P1, P2 dan C2) ditancapkan ke tanah dalam satu baris dengan jarak masing-masing a meter. Antara P1 dan P2 dipasang Voltmeter, antara C1 
dan C2 disambungkan dengan Ampere meter dan sumber daya AC 110/220 VAC.

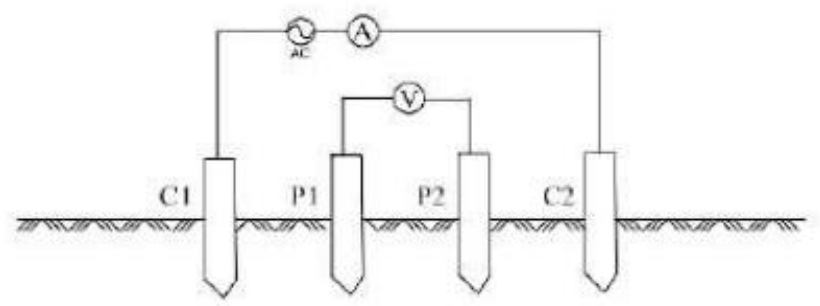

Gambar 2. Metode Empat Titik (Fluke Corporation)

Cara pengukuran:

Sambungkan sumber daya, ukur berapa Ampere arus yang mengalir antara $\mathrm{C} 1$ dan $\mathrm{C} 2$, misalnya I Ampere. Ukur berapa beda potensial antara P1 dan P2, misalnya V (Volt). Masukkan besaran pada rumus:

$\rho=2 \pi \mathrm{aR}$

dengan

$\pi=3,14$

$\mathrm{a}=$ jarak antara batang besi $(\mathrm{m})$

\section{b. Metoda Tiga Titik (three-point methode)}

Misalkan tiga buah batang pentanahan dimana batang 1 yang tahanannya hendak diukur dan batang-batang 2 dan 3 batang pengentanahan pembantu yang diketahui tahanannya (Fluke Corporation, 2017)seperti pada gambar 3.

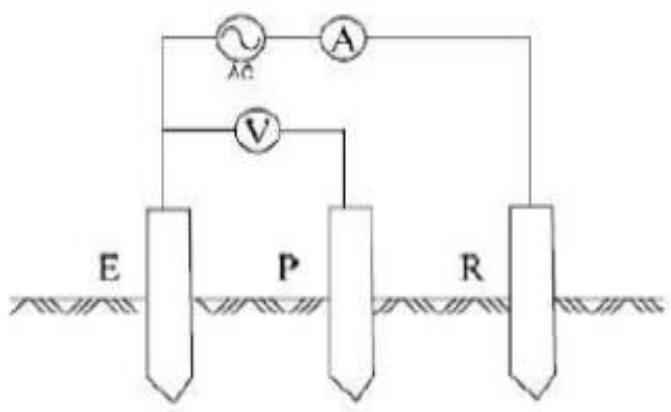

Gambar 3. Metoda Tiga Titik

\section{METODOLOGI PENELITIAN}

Untuk mengetahui apakah tahanan pentanahan di Rusunawa sesuai dengan standar, maka diperlukan pengukuran tahanan pentanahan tersebut. Elektroda yang digunakan pada pengukuran terbuat dari tembaga dengan diameter $4 \mathrm{~mm}$ yang dipasang vertikal atau ditanam di tanah Rusunawa dengan kondisi tanah kering.

Metode three point method (metode pengukuran 3 titik), dilakukan dengan urutan sebagai berikut :

1. Tanamlah satu batang elektroda dan dua buah elektroda kutub tanah batang penolong, yang terletak pada satu garis lurus dengan jarak yang sudah ditentukan. Dan rangkai seperti gambar berikut : 


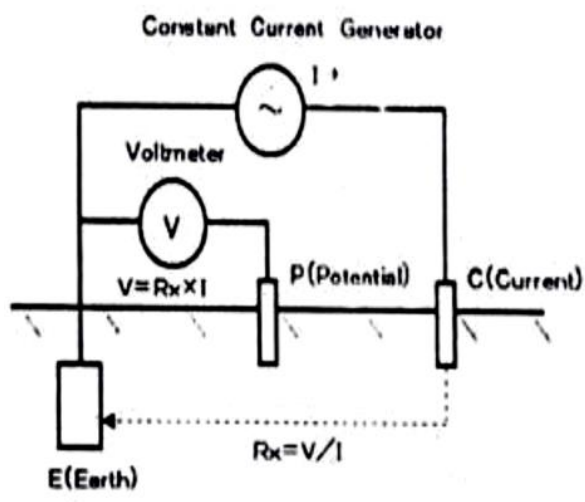

Gambar 2. Metode fall of potential

2. Amati penunjukan ampere-meter dan volt-meter. Besar tahanan pentanahan adalah :

$$
\mathrm{R}=\frac{V}{I}
$$

\section{Tahanan Pentanahan}

Nilai tahanan pentanahan dipengaruhi oleh tahanan jenis tanah dan metode sistem pentanahannya. Pada penelitian ini penulis juga menghitung $\rho$ (Rho) massa jenisnya dengan metode driven rod dan metode schlumberger sebagai berikut :

$$
\begin{array}{ll}
\text { 1. Metode Driven Rod } & : R=\frac{\rho}{2 \pi \mathrm{L}}\left[\ln \left(\frac{4 L}{a}\right)-1\right] \text { dan } \\
\text { 2. Metode Schlumberger } & : \rho=\frac{2 \pi \mathrm{LR}}{\left[\ln \left(\frac{4 L}{a}\right)-1\right]}
\end{array}
$$

Dimana :

$$
\begin{aligned}
\mathrm{R} & =\text { Tahanan Pembumian Elektroda Batang }(\mathrm{ohm}) \\
\rho & =\operatorname{tahanan} \text { jenis tanah }(\mathrm{ohm} \cdot \mathrm{m}) \\
\pi & =3.14 \text { atau }(22 / 7) \\
\mathrm{L} & =\text { panjang elektroda }(\mathrm{m}) \\
a & =\text { jari-jari elektroda }(\mathrm{m})
\end{aligned}
$$

\section{ANALISA DAN PEMBAHASAN}

Pengukuran tahanan pentanahan bertujuan untuk mengetahui besarnya tahanan pentahanan dari beberapa kondisi tanah. Nilai tahanan pentanahan yang baik yaitu $0 \Omega-5 \Omega$. Untuk nilai tahanan pentanahan di berbagai tempat itu berbeda sesuai dengan kondisi tanahnya.

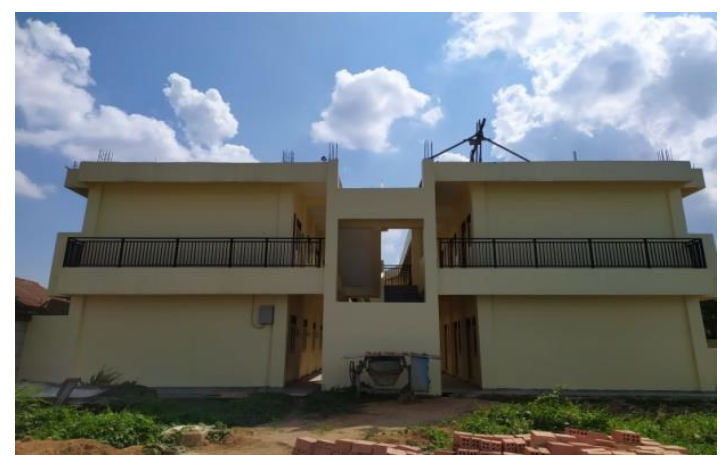

Gambar 4 Rusunawa Universitas PGRI Palembang 
Hasil pengukuran dilakukan pada tanah sekitar rusunawa dengan kedalaman bervariasi antar 0,$8 ; 1 ; 1,2$ meter.

Tabel 3. Hasil Pengukuran

\begin{tabular}{|c|c|c|c|}
\hline No. & $\begin{array}{c}\text { Kedalaman } \\
\text { (meter) }\end{array}$ & $\begin{array}{c}\text { Hasil Ukur } \\
\text { (Volt Meter) }\end{array}$ & $\begin{array}{c}\text { Hasil Ukur } \\
\text { (Ampere Meter) }\end{array}$ \\
\hline $\mathbf{1 .}$ & 0,8 & 2,19 volt & 0,05 ampere \\
\hline $\mathbf{2 .}$ & 1 & 1,75 volt & 0,05 ampere \\
\hline $\mathbf{3 .}$ & 1,2 & 1,45 volt & 0,05 ampere \\
\hline
\end{tabular}

Untuk mendapatkan nilai pentanahan, terlebih dahulu dilakukan perhitungan nilai tahanan jenis. Hasilnya dapat dilihat pada tabel 4.

Tabel 4. Hasil Penghitungan Tahanan Pentanahan dan Tahanan Jenis Tanahnya

\begin{tabular}{|c|c|c|}
\hline No. & $\begin{array}{c}\text { Kedalaman } \\
\text { (meter) }\end{array}$ & $\begin{array}{c}\text { Tahanan Jenis Tanahnya } \\
\text { (Ohm.m) }\end{array}$ \\
\hline $\mathbf{1 .}$ & 0,8 & $5,212 \Omega \cdot \mathrm{m}$ \\
\hline $\mathbf{2 .}$ & 1 & $4,165 \Omega \cdot \mathrm{m}$ \\
\hline $\mathbf{3 .}$ & 1,2 & $3,451 \Omega \cdot \mathrm{m}$ \\
\hline
\end{tabular}

Dari hasil perhitungan didapat nilai tahanan jenis tanah pada kedalaman 0,8 meter sebesar 52,12 ohm.meter, untuk kedalaman 1 meter sebesar 41,12 ohm. meter sedangkan untuk kedalaman 1,2 1,2 meter sebesar 34,51 ohm.meter. Nilai tahanan pentanahan yang ada di Rusunawa Universitas PGRI Palembang dapat dilihat pada tabel 4. Semakin dalam penanaman batang elektroda maka akan semakin kecil nilai resistansi pentanahannya.

Tabel 4. Perbandingan Hasil Pengukuran dan Penghitungan Tahanan Pentanahan

\begin{tabular}{|c|c|c|c|}
\hline \multirow[t]{2}{*}{ No. } & \multirow[t]{2}{*}{$\begin{array}{c}\text { Kedalaman } \\
\text { (meter) }\end{array}$} & \multicolumn{2}{|c|}{$\begin{array}{c}\text { Tahanan Pentanahan } \\
(\text { Ohm })\end{array}$} \\
\hline & & Pengukuran & Perhitungan \\
\hline 1. & 0,8 & 5 & $4,38 \Omega$ \\
\hline 2. & 1 & 4,2 & $3,5 \Omega$ \\
\hline 3. & 1,2 & 3,4 & $2,9 \Omega$ \\
\hline
\end{tabular}

\section{KESIMPULAN}

Tahanan jenis tanah memepengaruhi besarnya nilai tahanan pentahanan. Besarnya tahanan jenis jenis tanah dipengaruhi oleh kedalaman penanaman batang elektroda. Semakin dalam elektroda batang ditanam maka semakin kecil pula nilai tahanan pentanahannya.

\section{DAFTAR PUSTAKA}

[1] Mirwan Mukmin PERBANDINGAN NILAI TAHANAN PENTANAHAN PADA AREA REKLAMASI PANTAI (CITRALAND) Jurnal MEKTRIK Vol. 1 No. 1, September 2014

[2] Aris Sunawar, Analisis Pengaruh Temperatur dan Kadar Garam Terhadap Hambatan Jenis Tanah SETRUM - Volume 2, No. 1, Juni 2013 ISSN : 2301-4652

[3] Muhammad Taqiyyuddin Alawiy, Pengaruh Kedalaman Penanaman dan Jarak Elektroda Tambahan TerhadapNilai Tahanan Pembumian, Universitas Islam, Malang, . (2013). 
[4] Ahmad Budiman, 2017. Analisa Perbandingan Tahanan Pembumian Peralatan Elektroda Pasak Pada Gedung Laboratorium Teknik Universitas Borneo Tarakan. JNTE Unand Vol 6 no 3 November 2017

[5] Hutauruk, T.S. 1999. Pengetanahan Netral Sistem Tenaga dan PengetanahanPeralatan. Erlangga.

[6] Wahyono Pengaruh Kedalaman Elektroda batang Tunggal terhadap Nilai Pentanahan Pada Tanah Liat dan Soiltreatment Garam Eksergi Jurnal Teknik Energi Vol 8 No. 1 Januari 2012; 1 - 6

[7]Vicky Salamena. "PENGARUH KEDALAMAN ELEKTRODA TERHADAP PENGUKURAN TAHANAN JENIS: TANAH, PASIR DAN AIRLAUT DI PULAU AMBON DENGAN KONFIGURASI WENNER ALFA", JURNAL SIMETRIK, 2018

[8] IEEE Std 142-2007. IEEE Recommended Practice for Grounding of Industrial and Commercial Power Systems, (2007).

[9] Avianti, F. 2012. Pengujian Dan Analisa Tahanan Elektroda Pentanahan Dengan Metode 3 Kutub Pada Gtt Bengkel Listrik, Politeknik Negeri Malang, Tugas Akhir Politeknik Negeri Malang, Malang.

[10] Fluke Corporation, 2017. Prinsip, Metode Pengujian dan Aplikasi. 